\title{
AN ENHANCEMENT EDAS METHOD BASED ON PROSPECT THEORY
}

\author{
Yuhan $\mathrm{HUANG}^{1}$, Rui $\mathrm{LIN}^{2}$, Xudong $\mathrm{CHEN}^{3 *}$ \\ ${ }^{1}$ Institute of Fundamental and Frontier Sciences, University of Electronic Science \\ and Technology of China, Chengdu, 610054 Sichuan, P.R. China \\ ${ }^{2}$ School of Economics and Management, Chongqing University of Arts and Sciences, \\ 402160 Chongqing, P.R. China \\ ${ }^{3}$ School of Accounting, Southwestern University of Finance and Economics, \\ 610074 Chengdu, P.R. China
}

Received 21 January 2021; accepted 05 April 2021

\begin{abstract}
Decision-making is the process of carefully considering multiple options and choosing the best one. The EDAS (evaluation based on distance from average solution) method has been studied in many multi-attributes decision-making (MADM) problem which assumes decisionmaking under absolute rationality. However, people usually show the characteristics of bounded rationality in the real decision-making process. Prospect theory (PT) utilizes gains and losses relative to the reference point to explain this phenomenon better. In this paper, an enhancement EDAS method based on PT will be proposed, which shows better properties in practice. We apply the traditional EDAS method and enhancement EDAS method to the same case and we utilize the sensitivity analysis and comparative analysis to analyze their performances. The result shows that our approach has a superiority compared with the traditional EDAS method. The methods we present are of great significance for investment decision-making problems, new product development, design plan selection and supplier selection.
\end{abstract}

Keywords: decision-making, bounded rationality, EDAS, PT, sensitivity analysis.

JEL Classification: C43, C61, D81.

\section{Introduction}

Multi-attribute decision-making (MADM) is a decision-making problem in which multiple attributes or indicators are considered, and the best alternatives or alternatives with limited ranking are selected (Rostamzadeh et al., 2017; Tabatabaei et al., 2019; Wang et al., 2021). Hillier (2012) first used the simple weighting method to solve the MADM problem of business investment strategy. In the 1970s, the analytic hierarchy process (AHP) was a decision-

*Corresponding author. E-mail: xutung99@126.com

Copyright (c) 2021 The Author(s). Published by Vilnius Gediminas Technical University

This is an Open Access article distributed under the terms of the Creative Commons Attribution License (http://creativecommons. org/licenses/by/4.0/), which permits unrestricted use, distribution, and reproduction in any medium, provided the original author and source are credited. 
making procedure initially developed by Saaty (1977). In 1981, Yoon and Hwang (1981) proposed the TOPSIS method based on the ideal point principle and TOPSIS method were used in more and more domains. After that, researchers have proposed a MADM method based on artificial intelligence technology (Cheng \& Chang, 2006; Ren et al., 2019), neural network (Bagherzadeh \& Gholizadeh, 2017; Hashiyama et al., 1993), evolutionary programming (Fallahpour et al., 2017; Tian et al., 2018), rough set theory (Malik \& Shabir, 2019; Pawlak \& Sowinski, 1994) and different fuzzy and uncertain setting (Roy et al., 2019; Wei et al., 2021a, 2021b). Keshavarz Ghorabaee Zavadskas, Olfat, and Turskis (2015) in 2015 introduced the Evaluation based on the Distance from Average Solution (EDAS) method. He et al. (2020) defined the pythagorean 2-tuple linguistic EDAS. He et al. (2019) proposed the probabilistic uncertain linguistic EDAS. In most of the above methods, rational decision theory occupies an absolute dominant position. The rational decision theory is developed based on the expected utility theory proposed by Morgenstern and Von Neumann (1953). It is assumed that the expected utility is "completely rational". It is believed that the DM can correctly obtain all the information needed for the decision-making and make decisions based on this information. However, some empirical studies have shown that expected utility theory cannot explain many behavioral anomalies in reality. In 1945, Barnard and Simon (1947), the winner of the Nobel Prize in Economics, pointed out that neither rational nor economic standards can accurately explain managers' decision-making process and then put forward the concept of bounded rationality. Review the research results of economics and psychology in decision-making. Professor Kahneman (1979), the founder of behavioral economics, put forward the PT, marking that behavioral decision-making theory has become an essential subject of decision-making science research. In 1992, Amos Tversky and Daniel Kahneman (1992) extended the original PT based on the hierarchy-dependent utility theory, and proposed the cumulative prospect theory (CPT). It replaced the scattered probability weights in the PT with incremental probability weights, gave a value function, and calculated the probability weight function. In 2008, Schmidt, Starmer, and Sugden (2008) proposed the third-generation theory for the uncertain reference point. In 2009, Schmidt and Zank (2009) proposed a simplified CPT model to solve uncertain decision problems. Wakker (2007) published the most comprehensive book on PT research in 2010. At present, the research on the decision-making method of PT is pervasive. Gomes and Lima (1992) proposed a TODIM method based on PT. This method compares the two alternatives by constructing the dominance degree of one alternative to sort schemes. After that, Salminen (1994) proposed an interactive MADM method based on PT. Lahdelma and Salminen (2009) proposed the SMAA method based on PT. To solve the risky multi-attribute problem, Liu and Zhang (2010), Wang and Zhang (2009) and Liu, Jin, Zhang, Su, and Wang (2011) respectively proposed decision-making methods based on PT. In 2017, Wang, Wang, and Martínez (2017) proposed a hesitant fuzzy TOPSIS MADM method based on PT. In 2019, Tian, $\mathrm{Xu}$, and $\mathrm{Gu}$ (2019) proposed an extended TODIM method based on CPT. Zhao, Wei, Wei, Wu, and Wei (2021b) defined the interval-valued intuitionistic fuzzy TODIM based on CPT. Zhao, Wei, Wei, and Wu (2021d) defined the Pythagorean Fuzzy TODIM based on CPT. Zhao, Wei, Wu, Guo, and Wei (2021c) developed the 2-tuple linguistic neutrosophic TODIM method based on CPT. Zhao, Wei, Wei, and Guo (2021a) defined the bipolar fuzzy TODIM based on CPT. Zhang, Wei, Guo, and Wei (2021) defined the 2-tuple linguistic Py- 
thagorean fuzzy TODIM based on CPT. The research on sensitivity analysis has produced many results. Myers and Alpert (1968) studied the influence of the change of a certain attribute's weight on the result of scheme ranking. Starr (1966), Fishburn, Murphy, and Isaacs (1968), and Evans (1984), etc., studied the largest change area of attribute weights under the same scheme ranking condition. For the AHP, Masuda (1990) and Armacost and Hosseini (1994) separately studied sensitivity analysis methods. Therefore, we intend to construct an enhancement EDAS method that integrates the merit of both classical EDAS, PT, and CPT to portray decision makers' (DMs') psychological states to match the fundamental nature of the practical decision-making environment. The main contributions of this study can be summarized as follows: (1) Extending the classical EDAS method based on PT and CPT. (2) Comparing the enhancement EDAS methods with the original EDAS, TODIM and the extended TODIM method, the effectiveness of the enhancement EDAS method is obtained.

(3) Through sensitivity analysis, we know that the enhancement EDAS can demonstrate the bounded rationality effect of PT. It has enriched VCs' decision-making method and made a reasonable demonstration role for the uncertain decision-making in the other field. The rest of the study is organized as follows: Section 1 briefly introduces the basis of PT. Section 2, combining the PT with the EDAS method and proposing the enhancement EDAS method's steps. In Section 3, we carried out a case calculation on the enhancement EDAS methods. Through comparative analysis and sensitivity analysis, we confirmed the effectiveness and superiority of the enhancement EDAS methods. Finally, the last Section infers the study with some conclusions.

\section{Prospect Theory}

PT is a kind of behavioral decision-making theory that describes the actual decision-making process of individuals. It can explain many abnormal phenomena that can't be explained by expected utility theory and can reflect DMs' actual behavior. In this section, we briefly introduce $\mathrm{PT}^{1}, \mathrm{CPT}$.

\subsection{First-generation Prospect Theory}

It is a well-known theory to explain some behavioral biases proposed by Tversky and Kahneman (1979). This theory's essential part can be constructed as the value function $v(x)$ and the probability weighting function $\pi(p)$.

\subsubsection{Value function}

The figure of value function given by Tversky and Kahneman (1979) is shown in Figure 1. The expression of the value function is:

$$
v(x)=\left\{\begin{array}{c}
x^{\alpha}, x \geq 0 \\
-\lambda(-x)^{\beta}, x<0
\end{array},\right.
$$

where $\alpha$ and $\beta$ respectively represent the concavity of income and loss regions of the value function, $0 \leq \alpha, \beta \leq 1$. $\lambda$ reflects the degree of decision markers' loss avoidance, which is used to represent the steeper feature of the loss area of the value function than the gain area, $\lambda \geq 1$. 


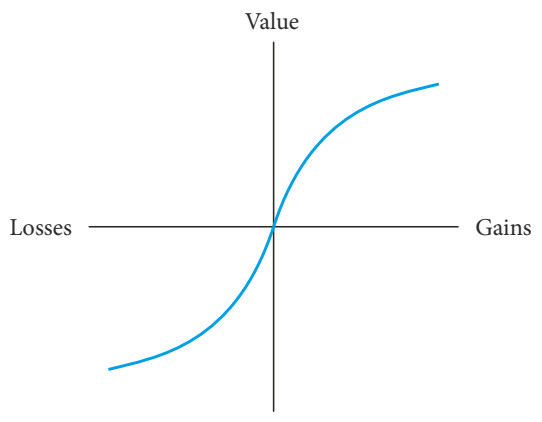

Figure 1. The value function of PT

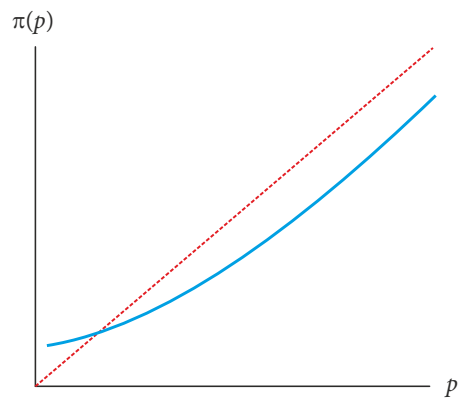

Figure 2. The probability weighting function of PT

\subsubsection{Probability weighting function}

The figure of the probability weighting function given by Tversky and Kahneman (1979) is shown in Figure 2. The $\mathrm{p}$ represents the probability of the event that happened. $\pi(p)$ represents the probability of the weight of $p$.

\subsection{Cumulative prospect theory}

To solve the limitation that the probability weighting function of PT dose did not satisfy the limits of random possession, the CPT was proposed by Tversky and Kahneman (1992). Let a Prospect $\mathrm{P}$ be $\left(p_{1}, x_{1} ; p_{2}, x_{2} \ldots p_{k}, x_{k}\right)$, where $x_{i}$ 's probability is $p_{i}$ (the probability weighting function from Figure 3 ). Let the reference point $x_{0}=0$, rank all the results in ascending order, and re-write as $x_{-m} \leq \ldots \leq x_{0} \leq x_{1} \leq \ldots \leq x_{n}$. The prospect value $V(P)$ was defined as:

$$
V(P)=V\left(P^{+}\right)+V\left(P^{-}\right)
$$

where

$$
\begin{gathered}
V\left(P^{+}\right)=\sum_{i=0}^{n} \pi_{i}^{+} v\left(x_{i}\right) \\
V\left(P^{-}\right)=\sum_{i=-m}^{0} \pi_{i}^{-} v\left(x_{i}\right),
\end{gathered}
$$

where $v\left(x_{i}\right)$ is the value of result $x_{i}$, and the calculation formula is Eq. (1). $\pi_{i}^{+}$and $\pi_{i}^{-}$are the probability weights of gains and losses, and the calculation formula is:

$$
\begin{gathered}
\pi_{i}^{+}=\left\{\begin{array}{cc}
w^{+}\left(p_{i}\right), & i=n \\
w^{+}\left(p_{i}+\ldots+p_{n}\right)-w^{+}\left(p_{i+1}+\ldots+p_{n}\right), & 0 \leq i \leq n-1
\end{array} ;\right. \\
\pi_{i}^{-}=\left\{\begin{array}{cc}
w^{-}\left(p_{-m}+\ldots+p_{i}\right)-w^{-}\left(p_{-m}+\ldots+p_{i-1}\right), & 1-m \leq i \leq 0 \\
w^{-}\left(p_{i}\right), & i=-m
\end{array},\right.
\end{gathered}
$$

where

$$
w^{+}(p)=\frac{p^{\gamma}}{\left(p^{\gamma}+(1-p)^{\gamma}\right)^{1 / \gamma}}
$$




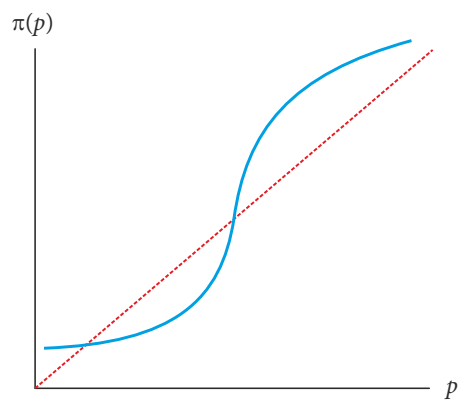

Figure 3 . The probability weighting function of CPT

$$
w^{-}(p)=\frac{p^{\delta}}{\left(p^{\delta}+(1-p)^{\delta}\right)^{1 / \delta}},
$$

$\gamma$ and $\delta$ as parameters respectively represents the bending degree of the probability weight functions of gain and loss, reflecting the different attitudes of DMs toward the risk of gains and the losses, $\gamma>0, \delta>0$.

\section{Enhancement EDAS methods based on prospect theory}

This section introduces the EDAS method and explains how we combining $\mathrm{PT}^{1}, \mathrm{CPT}$, with the classical EDAS method enable the enhancement EDAS Methods to optimize the DMs' selection process.

\subsection{Classical EDAS method}

The classical EDAS method is applied to MADM under the condition of independent attributes (Keshavarz Ghorabaee et al., 2016). Calculating every alternative's distance from the average value to help DMs find the best solution. The MADM problem includes the available alternatives $A=\left\{A_{1}, \ldots, A_{n}\right\}$ and the attributes $C=\left\{C_{1}, \ldots, C_{m}\right\}$. The input information is illustrated as a decision matrix $R$ which acquired from DMs, as shown in Eq. (9).

$$
R=\left(\begin{array}{ccc}
r_{11} & \cdots & r_{1 n} \\
\vdots & \ddots & \vdots \\
r_{m 1} & \cdots & r_{m n}
\end{array}\right),
$$

where $r_{i j}$ is the value of the $j_{\text {th }}$ attribution of alternative $i$ from DMs.

Step 1. The normalized values of the decision matrix R equaled Eq. (10):

$$
\bar{r}_{i j}=\frac{r_{i j}}{\sum_{i=1}^{n} r_{i j}} .
$$

Step 2. Eq. (11) is accustomed to determine the degree of entropy:

$$
E_{j}=-\frac{1}{\ln n} \sum_{i=1}^{n} \bar{r}_{i j} \cdot \ln \bar{r}_{i j}, j=1, \ldots, n \text {. }
$$


Step 3. At this stage, the entropy weight is acquired from Eq. (12):

$$
w_{j}=\frac{1-E_{j}}{\sum_{i=1}^{n}\left(1-E_{j}\right)} .
$$

Step 4. The average solution of every attribution is determined:

$$
\mathrm{AV}_{j}=\frac{\sum_{i=0}^{m}, j=1, \ldots, n .}{m},
$$

Step 5. Since there are positive and negative attribution types, the positive distance from average (PDA) and negative distance from average (NDA) of the positive attributes are represented by Eqs (14) and (15), respectively:

$$
\begin{gathered}
\mathrm{PDA}_{i j}=\frac{\max \left(0,\left(r_{i j}-\mathrm{AV}_{j}\right)\right)}{\mathrm{AV}_{j}}, i=1, \ldots, m, j=1, \ldots, n ; \\
\mathrm{NDA}_{i j}=\frac{\max \left(0,\left(\mathrm{AV}_{j}-r_{i j}\right)\right)}{\mathrm{AV}_{j}}, i=1, \ldots, m, j=1, \ldots, n .
\end{gathered}
$$

Eqs (16) and (17) represent the PDA and NDA of the negative attributes, respectively:

$$
\begin{aligned}
\mathrm{PDA}_{i j} & =\frac{\max \left(0,\left(\mathrm{AV}_{j}-r_{i j}\right)\right)}{\mathrm{AV}_{j}}, i=1, \ldots, m, j=1, \ldots, n ; \\
\mathrm{NDA}_{i j} & =\frac{\max \left(0,\left(r_{i j}-\mathrm{AV}_{j}\right)\right)}{\mathrm{AV}_{j}}, i=1, \ldots, m, j=1, \ldots, n .
\end{aligned}
$$

Step 6. Considering the weight of attribution, Eqs (18) and (19) are used to ensure the value of weighted PDA and weighted NDA of every alternative, respectively:

$$
\begin{aligned}
\mathrm{SP}_{i} & =\sum_{j=1}^{n} \mathrm{PDA}_{i j} w_{j}, i=1, \ldots, m ; \\
\mathrm{SN}_{i} & =\sum_{j=1}^{n} \mathrm{NDA}_{i j} w_{j}, i=1, \ldots, m .
\end{aligned}
$$

Step 7. Normalize the value of the weighted PDA and weighted NDA:

$$
\begin{gathered}
\mathrm{NSP}_{i}=\frac{\mathrm{SP}_{i}}{\max _{i}\left(\mathrm{SP}_{i}\right)}, i=1, \ldots, m ; \\
\mathrm{NSN}_{i}=1-\frac{\mathrm{SN}_{i}}{\max _{i}\left(\mathrm{SN}_{i}\right)}, i=1, \ldots, m .
\end{gathered}
$$

Step 8. The appraisal score for every alternative is:

$$
\mathrm{AS}_{i}=\frac{1}{2}\left(\mathrm{NSP}_{i}+\mathrm{NSN}_{i}\right), i=1, \ldots, m .
$$

Step 9. The appraisal scores for every alternative are arranged in descending order to make the final ranking of alternatives. 


\subsection{An enhancement EDAS method based on First-generation Prospect Theory}

The enhancement EDAS method based on First-generation Prospect Theory (PT ${ }^{1}$-EDAS) is defined in this section. Identify the decision matrix $R$, as shown:

$$
R=\left(\begin{array}{ccc}
r_{11} & \cdots & r_{1 n} \\
\vdots & \ddots & \vdots \\
r_{m 1} & \cdots & r_{m n}
\end{array}\right)
$$

and the weights of attribute are calculated by Eqs (10) to (12).

Step 1. Average every attribution by Eq. (13).

Step 2. Work out the PDA and NDA of the positive attributes are represented by Eqs (24) and (25).

$$
\begin{aligned}
& \mathrm{PDA}_{i j}=\left\{\begin{array}{l}
\frac{\max \left(0,\left(r_{i j}-\mathrm{AV}_{j}\right)^{\alpha}\right)}{\mathrm{AV}_{j}}, r_{i j}-\mathrm{AV}_{j} \geq 0 \\
\frac{\max \left(0,-\lambda\left(\mathrm{AV}_{j}-r_{i j}\right)^{\beta}\right)}{\mathrm{AV}_{j}}, r_{i j}-\mathrm{AV}_{j}<0
\end{array}, i=1, \ldots, m, j=1, \ldots, n ;\right. \\
& \mathrm{NDA}_{i j}=\left\{\begin{array}{l}
\frac{\max \left(0, \lambda\left(\mathrm{AV}_{j}-r_{i j}\right)^{\beta}\right)}{\mathrm{AV}_{j}}, \mathrm{AV}_{j}-r_{i j} \geq 0 \\
\frac{\max \left(0,-\left(r_{i j}-\mathrm{AV}_{j}\right)^{\alpha}\right)}{\mathrm{AV}_{j}}, \mathrm{AV}_{j}-r_{i j}<0
\end{array}, i=1, \ldots, m, j=1, \ldots, n .\right.
\end{aligned}
$$

Besides, the PDA and NDA of the negative attributes are represented by Eqs (26) and (27), respectively:

$$
\begin{aligned}
& \mathrm{PDA}_{i j}=\left\{\begin{array}{l}
\frac{\max \left(0,\left(\mathrm{AV}_{j}-r_{i j}\right)^{\alpha}\right)}{\mathrm{AV}_{j}}, \mathrm{AV}_{j}-r_{i j} \geq 0 \\
\frac{\max \left(0,-\lambda\left(r_{i j}-\mathrm{AV}_{j}\right)^{\beta}\right)}{\mathrm{AV}_{j}}, \mathrm{AV}_{j}-r_{i j}<0
\end{array}, i=1, \ldots, m, j=1, \ldots, n ;\right. \\
& \mathrm{NDA}_{i j}=\left\{\begin{array}{l}
\frac{\max \left(0, \lambda\left(r_{i j}-\mathrm{AV}_{j}\right)^{\beta}\right)}{\mathrm{AV}_{j}}, r_{i j}-\mathrm{AV}_{j} \geq 0 \\
\frac{\max \left(0,-\left(\mathrm{AV}_{j}-r_{i j}\right)^{\alpha}\right)}{\mathrm{AV}_{j}}, r_{i j}-\mathrm{AV}_{j}<0
\end{array}, i=1, \ldots, m, j=1, \ldots, n .\right.
\end{aligned}
$$


Step 3. Calculate the value of weighted PDA and weighted NDA of every alternative by Eqs (18) and (19), with the weight of attribution.

Step 4. Determine the appraisal score for every alternative by Eq. (28).

$$
\mathrm{AS}_{i}=\frac{1}{2}\left(\mathrm{SP}_{i}+\max _{i}\left(\mathrm{SN}_{i}\right)-\mathrm{SN}_{i}\right), i=1, \ldots, m .
$$

Step 5. Normalize the value of the appraisal score from Eq. (29).

$$
\mathrm{NAS}_{i}=\mathrm{AS}_{i} / \max _{i}\left(\mathrm{AS}_{i}\right), i=1, \ldots, m \text {. }
$$

Step 6. Arrange the appraisal scores for every alternative in descending order to make the final ranking of alternatives.

\subsection{An enhancement EDAS method based on Cumulative Prospect Theory}

The enhancement EDAS method based on CPT (CPT-EDAS) is defined in this section. Identify the decision matrix $R$ is represented by Eq. (23), and the weights of attribute are calculated by Eqs (10) to (12).

Step 1. Average every attribution by Eq. (13).

Step 2. Work out the PDA and NDA of the positive attributes are represented by Eqs (24) and (25). Besides, the PDA and NDA of the negative attributes are represented by Eqs (26) and (27).

Step 3. Will $r_{i j}-\mathrm{AV}_{j}$ notated as $x_{i j}, i=1, \ldots, m$. A ranking of $x_{i j}$ ascend like $x_{\left(-m^{-}\right) j} \leq$ $x_{\left(-m^{-}+1\right) j} \leq \ldots \leq x_{(-1) j} \leq 0 \leq x_{(1) j} \leq x_{\left(m^{+}\right) j}$. Then, probability weight can be expressed by:

where

$$
\pi_{i j}=\left\{\begin{array}{c}
\pi^{+}\left(w_{i}\right), i=m^{+} \\
\pi^{+}\left(w_{i}+\ldots+w_{m^{+}}\right)-\pi^{+}\left(w_{i+1}+\ldots+w_{m^{+}}\right), 1 \leq i \leq m^{+}-1 \\
\pi^{-}\left(w_{-m^{-}}+\ldots+w_{i}\right)-\pi^{-}\left(w_{-m^{-}}+\ldots+w_{i-1}\right), 1 \leq i \leq m^{+}-1 \\
\pi^{-}\left(w_{i}\right), i=-m^{-}
\end{array},\right.
$$

$$
\begin{aligned}
& \pi^{+}(p)=\frac{p^{\gamma}}{\left(p^{\gamma}+(1-p)^{\gamma}\right)^{1 / \gamma}} \\
& \pi^{-}(p)=\frac{p^{\delta}}{\left(p^{\delta}+(1-p)^{\delta}\right)^{1 / \delta}} .
\end{aligned}
$$

Step 4. Calculate the value of weighted PDA and weighted NDA of every alternative by Eqs (33) and (34), with probability weight.

$$
\begin{aligned}
\mathrm{SP}_{i} & =\sum_{j=1}^{n} \mathrm{PDA}_{i j} \pi_{i j} ; i=1, \ldots, m ; \\
\mathrm{SN}_{i} & =\sum_{j=1}^{n} \mathrm{NDA}_{i j} \pi_{i j} ; i=1, \ldots, m .
\end{aligned}
$$


Step 5. Calculate the appraisal score for every alternative by Eq. (28).

Step 6. Normalize the value of the appraisal score from Eq. (29).

Step 7. Sort the appraisal scores for every alternative in descending order to rank the alternatives.

\section{Case study}

In this section, we consider a MADM problem, the investment bank intends to invest in the best choice of the enterprises (alternatives), and there are five enterprise $\mathrm{A}_{i}$ to choose from. Though five evaluation indicators (attributes): (1) $\boldsymbol{\Gamma}_{1}$ : output value $\left(10^{4} \$\right) ;(2) \Gamma_{2}$ : investment cost $\left(10^{4} \$\right)$; (3) $\boldsymbol{\Gamma}_{3}$ : sales volume $\left(10^{4} \$\right)$; (4) $\boldsymbol{\Gamma}_{4}$ : proportion of national income; (5) $\boldsymbol{\Gamma}_{5}$ : degree of environmental pollution. The investment bank looked at the company's performance in recent years, where $\boldsymbol{\Gamma}_{2}$ and $\boldsymbol{\Gamma}_{5}$ are the cost attribution, and the rest are of benefit type. Though that we are discuss the effectiveness and advantage of the enhancement EDAS methods. We integrate PT with the EDAS method to solve this example to discuss the effectiveness and advantage of the enhancement EDAS methods. Beyond the classical EDAS method adds PT's psychological implications, considering the true view of gain and loss. Although theoretically reasonable, we use the above examples to prove the effectiveness and superiority of the algorithm proposed in this paper. The comparison between our designed method and CPT-TODIM method (Tian, et al., 2019) shows that enhancement EDAS has great potential after considering PT.

We used enhanced EDAS methods for evaluation matrix of five schemes and five attributes, and it can be seen in Table 1.

Table 1. The evaluation matrix

\begin{tabular}{|c|c|c|c|c|c|}
\hline & $\boldsymbol{\Gamma}_{1}$ & $\boldsymbol{\Gamma}_{2}$ & $\boldsymbol{\Gamma}_{3}$ & $\boldsymbol{\Gamma}_{4}$ & $\boldsymbol{\Gamma}_{5}$ \\
\hline$A_{1}$ & 8350 & 6300 & 7035 & 0.7100 & 0.1800 \\
\hline$A_{2}$ & 6580 & 6975 & 6600 & 0.6200 & 0.2400 \\
\hline$A_{3}$ & 11000 & 5050 & 8800 & 0.7800 & 0.1100 \\
\hline$A_{4}$ & 8267 & 5380 & 5890 & 0.6400 & 0.2300 \\
\hline$A_{5}$ & 9730 & 5690 & 6100 & 0.6500 & 0.1800 \\
\hline
\end{tabular}

\subsection{The decisioning process with the classical EDAS method}

In this section, the classical EDAS is processed for the sake of to compare it with the enhancement methods, which decision-making information in Table 1 is adopted here. Then the normalized appraisal scores are calculated on the steps in section 3.1.

Step 1 to 3. The weight is acquired from Eqs (10) to (12) (see Table 2).

Table 2. The weight of the attributes

\begin{tabular}{|c|c|c|c|c|}
\hline $\boldsymbol{\Gamma}_{1}$ & $\boldsymbol{\Gamma}_{2}$ & $\boldsymbol{\Gamma}_{3}$ & $\boldsymbol{\Gamma}_{4}$ & $\boldsymbol{\Gamma}_{5}$ \\
\hline 0.1832 & 0.0808 & 0.1373 & 0.0456 & 0.5532 \\
\hline
\end{tabular}


Step 4. According to the decision-making information in Table 1, the average solution of every attribution is determined in Table 3.

Table 3. The average solution of the enhancement EDAS method based on the $\mathrm{PT}^{1}$

\begin{tabular}{|c|c|c|c|c|}
\hline $\boldsymbol{\Gamma}_{1}$ & $\boldsymbol{\Gamma}_{2}$ & $\boldsymbol{\Gamma}_{3}$ & $\boldsymbol{\Gamma}_{4}$ & $\boldsymbol{\Gamma}_{5}$ \\
\hline 8785.4 & 5879 & 6885 & 0.6800 & 0.1880 \\
\hline
\end{tabular}

Step 5. Use Eqs (14) to (15) to calculate the value of the PDA and NDA. It is shown in Table 4 and Table 5.

Table 4. The PDA of classical EDAS method

\begin{tabular}{|c|c|c|c|c|c|}
\hline & $\boldsymbol{\Gamma}_{1}$ & $\boldsymbol{\Gamma}_{2}$ & $\boldsymbol{\Gamma}_{3}$ & $\boldsymbol{\Gamma}_{4}$ & $\boldsymbol{\Gamma}_{5}$ \\
\hline$A_{1 V}$ & 0 & 0 & 0.0218 & 0.0441 & 0.0426 \\
\hline$A_{2 V}$ & 0 & 0 & 0 & 0 & 0 \\
\hline$A_{3 V}$ & 0.2521 & 0.1410 & 0.2781 & 0.1471 & 0.4149 \\
\hline$A_{4 V}$ & 0 & 0.0849 & 0 & 0 & 0 \\
\hline$A_{5 V}$ & 0.1075 & 0.0321 & 0 & 0 & 0.0426 \\
\hline
\end{tabular}

Table 5. The NDA of classical EDAS method

\begin{tabular}{|c|c|c|c|c|c|}
\hline & $\boldsymbol{\Gamma}_{1}$ & $\boldsymbol{\Gamma}_{2}$ & $\boldsymbol{\Gamma}_{3}$ & $\boldsymbol{\Gamma}_{4}$ & $\boldsymbol{\Gamma}_{5}$ \\
\hline$A_{1 V}$ & 0.0496 & 0.0716 & 0 & 0 & 0 \\
\hline$A_{2 V}$ & 0.2510 & 0.1864 & 0.0414 & 0.0882 & 0.2766 \\
\hline$A_{3 V}$ & 0 & 0 & 0 & 0 & 0 \\
\hline$A_{4 V}$ & 0.0590 & 0 & 0.1445 & 0.0588 & 0.2234 \\
\hline$A_{5 V}$ & 0 & 0 & 0.1140 & 0.0441 & 0 \\
\hline
\end{tabular}

Step 6-8. Considering the weight of attribution. Eqs (18) and (19) are used to ensure the weighted PDA value and weighted NDA of every alternative value. Then, normalize the value of the weighted PDA and weighted NDA by Eqs (20) and (21). Finally, the appraisal score for every alternative calculated by Eq. (22) is shown in Table 6.

Table 6. The appraisal scores of classical EDAS method

\begin{tabular}{|l|c|c|c|c|c|}
\hline & $A_{1}$ & $A_{2}$ & $A_{3}$ & $A_{4}$ & $A_{5}$ \\
\hline The classical EDAS & 0.5098 & 0 & 1 & 0.1597 & 0.5296 \\
\hline
\end{tabular}

Step 9. From Table 5, it is known that $\operatorname{AS}\left(A_{3}\right)>\operatorname{AS}\left(A_{5}\right)>\operatorname{AS}\left(A_{1}\right)>\operatorname{AS}\left(A_{4}\right)>\operatorname{AS}\left(A_{2}\right)$, that is to say, $A_{3} \succ A_{5} \succ A_{1} \succ A_{4} \succ A_{2}$. The ranking result means that alternative $\mathrm{A}_{3}$ is the best option, and the alternative $\mathrm{A}_{2}$ is the worst option. 


\subsection{The decisioning process with the enhancement EDAS method based on First-generation Prospect Theory}

This section considers the enhancement EDAS method based on $\mathrm{PT}^{1}$, and the calculation steps are as follows:

Step 1 to 3. According to the decision-making information in Table 1, the weight is acquired from Eqs (10) to (12), which shown in Table 2.

Step 4. Evaluation matrix proposed calculate the average evaluation value corresponding to every attribute by Eq. (13), which can be seen in Table 3.

Step 5. The basic idea of the EDAS method is the use of two distance measures, PDA and NDA. In this step, we work out the matrices of PDA and NDA by Eqs (24) to (27), where $\alpha=0.88, \beta=0.88, \lambda=2.25$. They are presented in Table 7 and Table 8 .

Step 6. Based on the Eqs (18) and (19), the value of weighted PDA and weighted NDA of every alternative can be calculated with the weight of attribution. They can be seen in Table 9 and Table 10.

Step 7. The appraisal scores for every alternative are calculated by Eq. (28). It can be seen in Table 11.

Step 8. The appraisal scores for every alternative be normalized by Eq. (29). They can be presented in Table 12.

Step 9. The appraisal scores for every alternative are arranged in descending order, and the optimal solution is determined. It is known that $\operatorname{NAS}\left(A_{3}\right)>\operatorname{NAS}\left(A_{1}\right)>\operatorname{NAS}\left(A_{5}\right)>$ $\operatorname{NAS}\left(A_{4}\right)>\operatorname{NAS}\left(A_{2}\right)$, so $A_{3} \succ A_{1} \succ A_{5} \succ A_{4} \succ A_{2}$. We choose alternative $A_{3}$ is the best one, and $A_{2}$ is the worst one.

Table 7. The PDA of the enhancement EDAS method based on the $\mathrm{PT}^{1}$

\begin{tabular}{|c|c|c|c|c|c|}
\hline & $\boldsymbol{\Gamma}_{1}$ & $\boldsymbol{\Gamma}_{2}$ & $\boldsymbol{\Gamma}_{3}$ & $\boldsymbol{\Gamma}_{4}$ & $\boldsymbol{\Gamma}_{5}$ \\
\hline$A_{1 V}$ & 0 & 0 & 0.0119 & 0.0672 & 0.0756 \\
\hline$A_{2 V}$ & 0 & 0 & 0 & 0 & 0 \\
\hline$A_{3 V}$ & 0.1000 & 0.0630 & 0.1123 & 0.1939 & 0.5635 \\
\hline$A_{4 V}$ & 0 & 0.0403 & 0 & 0 & 0 \\
\hline$A_{5 V}$ & 0.0473 & 0.0171 & 0 & 0 & 0.0760 \\
\hline
\end{tabular}

Table 8. The NDA of the enhancement EDAS method based on the $\mathrm{PT}^{1}$

\begin{tabular}{|c|c|c|c|c|c|}
\hline & $\boldsymbol{\Gamma}_{1}$ & $\boldsymbol{\Gamma}_{2}$ & $\boldsymbol{\Gamma}_{3}$ & $\boldsymbol{\Gamma}_{4}$ & $\boldsymbol{\Gamma}_{5}$ \\
\hline$A_{1 V}$ & 0.0538 & 0.0780 & 0 & 0 & 0 \\
\hline$A_{2 V}$ & 0.2242 & 0.1811 & 0.0473 & 0.2783 & 0.8874 \\
\hline$A_{3 V}$ & 0 & 0 & 0 & 0 & 0 \\
\hline$A_{4 V}$ & 0.0627 & 0 & 0.1420 & 0.1948 & 0.7353 \\
\hline & 0 & 0 & 0.1153 & 0.1512 & 0 \\
\hline
\end{tabular}


Table 9. The weighted PDA of the enhancement EDAS method based on the PT ${ }^{1}$

\begin{tabular}{|c|c|c|c|c|}
\hline$A_{1}$ & $A_{2}$ & $A_{3}$ & $A_{4}$ & $A_{5}$ \\
\hline 0.0467 & 0 & 0.3594 & 0.0033 & 0.0521 \\
\hline
\end{tabular}

Table 10. The weighted NDA of the enhancement EDAS method based on the $\mathrm{PT}^{1}$

\begin{tabular}{|c|c|c|c|c|}
\hline$A_{1}$ & $A_{2}$ & $A_{3}$ & $A_{4}$ & $A_{5}$ \\
\hline 0.0162 & 0.5658 & 0 & 0.4466 & 0.0227 \\
\hline
\end{tabular}

Table 11. The appraisal scores of the enhancement EDAS method based on the $\mathrm{PT}^{1}$

\begin{tabular}{|c|c|c|c|c|}
\hline$A_{1}$ & $A_{2}$ & $A_{3}$ & $A_{4}$ & $A_{5}$ \\
\hline 0.2982 & 0 & 0.4626 & 0.0612 & 0.2975 \\
\hline
\end{tabular}

Table 12. The normalized appraisal scores of the enhancement EDAS method based on the $\mathrm{PT}^{1}$

\begin{tabular}{|c|c|c|c|c|}
\hline$A_{1}$ & $A_{2}$ & $A_{3}$ & $A_{4}$ & $A_{5}$ \\
\hline 0.6446 & 0 & 1 & 0.1323 & 0.6433 \\
\hline
\end{tabular}

\subsection{The decisioning process with the enhancement EDAS method based on Cumulative Prospect Theory}

This section considers the enhancement EDAS method based on CPT, which differs from the previous section is the probability weight of alternatives.

Steps 1 to 4. Following the same calculation steps and conclusions as to the 4.2 section.

Step 5. The probability weight can be expressed by Eq. (30) as shown in Table 13, where $\gamma=0.61, \delta=0.69$.

Table 13. The probability weight for every attribute

\begin{tabular}{|c|c|c|c|c|c|}
\hline & $\boldsymbol{\Gamma}_{1}$ & $\boldsymbol{\Gamma}_{2}$ & $\boldsymbol{\Gamma}_{3}$ & $\boldsymbol{\Gamma}_{4}$ & $\boldsymbol{\Gamma}_{5}$ \\
\hline$A_{1}$ & 0.2440 & 0.1677 & 0.1043 & 0.0265 & 0.3716 \\
\hline$A_{2}$ & 0.2440 & 0.1677 & 0.0971 & 0.0292 & 0.3255 \\
\hline$A_{3}$ & 0.2499 & 0.1496 & 0.0793 & 0.0236 & 0.3913 \\
\hline$A_{4}$ & 0.1354 & 0.0514 & 0.2056 & 0.0284 & 0.4484 \\
\hline$A_{5}$ & 0.2499 & 0.0649 & 0.2056 & 0.03244 & 0.3815 \\
\hline
\end{tabular}

Step 6. Calculate the value of weighted PDA and weighted NDA of every alternative by Eqs (33) and (34) with probability weight by Eqs (31) and (32). They are shown in Table 14 and Table 15.

Step 7. The appraisal scores calculated by Eq. (28). They can be presented in Table 16.

Step 8. The appraisal scores for every alternative are calculated by (29), which shown in Table 17. 
Step 9. The normalized appraisal scores for every alternative are sorted in descending order to rank the alternatives. It is known that $\operatorname{NAS}\left(A_{3}\right)>\operatorname{NAS}\left(A_{1}\right)>\operatorname{NAS}\left(A_{5}\right)>\operatorname{NAS}\left(A_{4}\right)>$ $\operatorname{NAS}\left(A_{2}\right)$, that is to say, $A_{3} \succ A_{1} \succ A_{5} \succ A_{4} \succ A_{2}$. The alternative $\mathrm{A}_{3}$ is recognized as the best option among the five alternatives and $A_{2}$ is the worst one.

Table 14. The weighted PDA of the enhancement EDAS method based on the CPT

\begin{tabular}{|c|c|c|c|c|}
\hline$A_{1}$ & $A_{2}$ & $A_{3}$ & $A_{4}$ & $A_{5}$ \\
\hline 0.0030 & 0 & 0.0385 & 0 & 0.0118 \\
\hline
\end{tabular}

Table 15. The weighted NDA of the enhancement EDAS method based on the CPT

\begin{tabular}{|c|c|c|c|c|}
\hline$A_{1}$ & $A_{2}$ & $A_{3}$ & $A_{4}$ & $A_{5}$ \\
\hline 0.0131 & 0.0674 & 0 & 0.0432 & 0.0286 \\
\hline
\end{tabular}

Table 16. The appraisal scores of the enhancement EDAS method based on the CPT

\begin{tabular}{|c|c|c|c|c|}
\hline$A_{1}$ & $A_{2}$ & $A_{3}$ & $A_{4}$ & $A_{5}$ \\
\hline 0.0287 & 0 & 0.0530 & 0.0121 & 0.0253 \\
\hline
\end{tabular}

Table 17. The normalized appraisal scores of the enhancement EDAS method based on the CPT

\begin{tabular}{|c|c|c|c|c|}
\hline$A_{1}$ & $A_{2}$ & $A_{3}$ & $A_{4}$ & $A_{5}$ \\
\hline 0.5412 & 0 & 1 & 0.2286 & 0.4781 \\
\hline
\end{tabular}

\subsection{The comparison of these methods}

In this section, we compare the results of this paper with those of the extended TODIM (Tian et al., 2019), the classical TODIM method (Gomes \& Rangel, 2009), and classical EDAS method (Keshavarz Ghorabaee et al., 2015) to test the enhancement EDAS methods' efficiency based on PT.

To show the effectiveness of the enhancement EDAS method proposed in this kind of paper, we illustrate other PT processes to solve the above cases. The methods include enhancement TODIM, the classical TODIM method. The calculation results are shown in Table 18.

Table 18. The appraisal scores of different methods

\begin{tabular}{|l|c|c|c|c|c|}
\hline & $A_{1}$ & $A_{2}$ & $A_{3}$ & $A_{4}$ & $A_{5}$ \\
\hline The extended TODIM & 0.5931 & 0 & 1 & 0.2978 & 0.4380 \\
\hline The classical TODIM & 0.5126 & 0 & 1 & 0.3338 & 0.4888 \\
\hline The enhancement EDAS based on PT & 0.6446 & 0 & 1 & 0.1323 & 0.6433 \\
\hline The enhancement EDAS based on CPT & 0.5412 & 0 & 1 & 0.2286 & 0.4781 \\
\hline The classical EDAS & 0.5098 & 0 & 1 & 0.1597 & 0.5296 \\
\hline
\end{tabular}


The results in Table 18 show that every method's ranking result are roughly the same, only the classical EDAS method ranks $A_{1}$ and scheme $A_{5}$ are slightly different from the other methods. The following conclusion is obtained that the evaluation ability of the enhancement EDAS methods are more inclined to the TODIM method, it proves that the effectiveness of the enhancement EDAS methods.

\subsection{The sensitivity analysis}

This section analyzes the sensitivity of parameters of the enhancement EDAS methods and concludes that the enhancement EDAS methods are superior to the classical one.

In the enhancement EDAS method, the calculation of distance (PDA and NDA) between the scheme $A_{i}$ and the schemes of average is essential. We now use the enhancement EDAS method based on $\mathrm{PT}^{1}$ to illustrate many options for PDA and NDA (The sensitivity analysis of the parameters in the CPT method is consistent with $\mathrm{PT}^{1}$, so we only present the $\mathrm{PT}^{1}$ method here). In section 3.2, the normalized appraisal scores under conditions of the parameters $\alpha=\beta=0.88$ and $\lambda=2.25$ in Eqs (24) and (25) are discussed.

a) Under conditions of $\alpha=\beta=0.88$, the effect of the change of $\lambda$ on the result.

The result of enhancement EDAS method based on $\mathrm{PT}^{1}$ under different values of $\lambda$ is shown in Table 19.

Table 19. the rank results of different values of $\lambda$

\begin{tabular}{|c|c|c|}
\hline$\lambda$ & NAS & rank \\
\hline \multirow{5}{*}{1} & $\operatorname{NAS}\left(A_{1}\right)=0.4764$ & \multirow{5}{*}{$A_{3} \succ A_{5} \succ A_{1} \succ A_{4} \succ A_{2}$} \\
\hline & $\operatorname{NAS}\left(A_{2}\right)=0$ & \\
\hline & $\operatorname{NAS}\left(A_{3}\right)=1$ & \\
\hline & $\operatorname{NAS}\left(A_{4}\right)=0.0920$ & \\
\hline & $\operatorname{NAS}\left(A_{5}\right)=0.4803$ & \\
\hline \multirow{5}{*}{2} & $\operatorname{NAS}\left(A_{1}\right)=0.6208$ & \multirow{5}{*}{$A_{3} \succ A_{1} \succ A_{5} \succ A_{4} \succ A_{2}$} \\
\hline & $\operatorname{NAS}\left(A_{2}\right)=0$ & \\
\hline & $\operatorname{NAS}\left(A_{3}\right)=1$ & \\
\hline & $\operatorname{NAS}\left(A_{4}\right)=0.1266$ & \\
\hline & $\operatorname{NAS}\left(A_{5}\right)=0.6202$ & \\
\hline \multirow{5}{*}{3} & $\operatorname{NAS}\left(A_{1}\right)=0.6999$ & \multirow{5}{*}{$A_{3} \succ A_{1} \succ A_{5} \succ A_{4} \succ A_{2}$} \\
\hline & $\operatorname{NAS}\left(A_{2}\right)=0$ & \\
\hline & $\operatorname{NAS}\left(A_{3}\right)=1$ & \\
\hline & $\operatorname{NAS}\left(A_{4}\right)=0.1455$ & \\
\hline & $\operatorname{NAS}\left(A_{5}\right)=0.6969$ & \\
\hline \multirow{5}{*}{4} & $\operatorname{NAS}\left(A_{1}\right)=0.7499$ & \multirow{5}{*}{$A_{3} \succ A_{1} \succ A_{5} \succ A_{4} \succ A_{2}$} \\
\hline & $\operatorname{NAS}\left(A_{2}\right)=0$ & \\
\hline & $\operatorname{NAS}\left(A_{3}\right)=1$ & \\
\hline & $\operatorname{NAS}\left(A_{4}\right)=0.1575$ & \\
\hline & $\operatorname{NAS}\left(A_{5}\right)=0.7453$ & \\
\hline
\end{tabular}


End of Table 19

\begin{tabular}{|c|c|c|}
\hline$\lambda$ & NAS & rank \\
\hline \multirow{5}{*}{5} & $\operatorname{NAS}\left(A_{1}\right)=0.7844$ & \multirow{5}{*}{$A_{3} \succ A_{1} \succ A_{5} \succ A_{4} \succ A_{2}$} \\
\hline & $\operatorname{NAS}\left(A_{2}\right)=0$ & \\
\hline & $\operatorname{NAS}\left(A_{3}\right)=1$ & \\
\hline & $\operatorname{NAS}\left(A_{4}\right)=0.1657$ & \\
\hline & $\operatorname{NAS}\left(A_{5}\right)=0.7787$ & \\
\hline
\end{tabular}

b) Under conditions of $\beta=0.88, \lambda=2.25$, the effect of the change of $\alpha$ on the result.

The result of enhancement EDAS method based on $\mathrm{PT}^{1}$ under different values of $\alpha$ is shown in Table 20.

Table 20. the rank results of different values of $\alpha$

\begin{tabular}{|c|c|c|}
\hline$\alpha$ & NAS & rank \\
\hline \multirow{5}{*}{0.1} & $\operatorname{NAS}\left(A_{1}\right)=0.8322$ & \multirow{5}{*}{$A_{3} \succ A_{1} \succ A_{5} \succ A_{4} \succ A_{2}$} \\
\hline & $\operatorname{NAS}\left(A_{2}\right)=0$ & \\
\hline & $\operatorname{NAS}\left(A_{3}\right)=1$ & \\
\hline & $\operatorname{NAS}\left(A_{4}\right)=0.0411$ & \\
\hline & $\operatorname{NAS}\left(A_{5}\right)=0.8136$ & \\
\hline \multirow{5}{*}{0.3} & $\operatorname{NAS}\left(A_{1}\right)=0.6422$ & \multirow{5}{*}{$A_{3} \succ A_{1} \succ A_{5} \succ A_{4} \succ A_{2}$} \\
\hline & $\operatorname{NAS}\left(A_{2}\right)=0$ & \\
\hline & $\operatorname{NAS}\left(A_{3}\right)=1$ & \\
\hline & $\operatorname{NAS}\left(A_{4}\right)=0.0606$ & \\
\hline & $\operatorname{NAS}\left(A_{5}\right)=0.6271$ & \\
\hline \multirow{5}{*}{0.5} & $\operatorname{NAS}\left(A_{1}\right)=0.5844$ & \multirow{5}{*}{$A_{3} \succ A_{1} \succ A_{5} \succ A_{4} \succ A_{2}$} \\
\hline & $\operatorname{NAS}\left(A_{2}\right)=0$ & \\
\hline & $\operatorname{NAS}\left(A_{3}\right)=1$ & \\
\hline & $\operatorname{NAS}\left(A_{4}\right)=0.0846$ & \\
\hline & $\operatorname{NAS}\left(A_{5}\right)=0.5720$ & \\
\hline \multirow{5}{*}{0.7} & $\operatorname{NAS}\left(A_{1}\right)=0.6062$ & \multirow{5}{*}{$A_{3} \succ A_{1} \succ A_{5} \succ A_{4} \succ A_{2}$} \\
\hline & $\operatorname{NAS}\left(A_{2}\right)=0$ & \\
\hline & $\operatorname{NAS}\left(A_{3}\right)=1$ & \\
\hline & $\operatorname{NAS}\left(A_{4}\right)=0.1110$ & \\
\hline & $\operatorname{NAS}\left(A_{4}\right)=0.5970$ & \\
\hline \multirow{5}{*}{0.9} & $\operatorname{NAS}\left(A_{1}\right)=0.6471$ & \multirow{5}{*}{$A_{3} \succ A_{1} \succ A_{5} \succ A_{4} \succ A_{2}$} \\
\hline & $\operatorname{NAS}\left(A_{2}\right)=0$ & \\
\hline & $\operatorname{NAS}\left(A_{3}\right)=1$ & \\
\hline & $\operatorname{NAS}\left(A_{4}\right)=0.1341$ & \\
\hline & $\operatorname{NAS}\left(A_{5}\right)=0.6473$ & \\
\hline
\end{tabular}


c) Under conditions of $\alpha=0.88, \lambda=2.25$, the effect of the change of $\beta$ on the result.

The result of enhancement EDAS method based on $\mathrm{PT}^{1}$ under different values of $\beta$ is shown in Table 21.

Table 21. the rank results of different values of $\beta$

\begin{tabular}{|c|c|c|}
\hline$\beta$ & NAS & rank \\
\hline \multirow{5}{*}{0.1} & $\operatorname{NAS}\left(A_{1}\right)=0.9421$ & \multirow{5}{*}{$A_{3} \succ A_{1} \succ A_{5} \succ A_{4} \succ A_{2}$} \\
\hline & $\operatorname{NAS}\left(A_{2}\right)=0$ & \\
\hline & $\operatorname{NAS}\left(A_{3}\right)=1$ & \\
\hline & $\operatorname{NAS}\left(A_{4}\right)=0.0207$ & \\
\hline & $\operatorname{NAS}\left(A_{5}\right)=0.9234$ & \\
\hline \multirow{5}{*}{0.3} & $\operatorname{NAS}\left(A_{1}\right)=0.9007$ & \multirow{5}{*}{$A_{3} \succ A_{1} \succ A_{5} \succ A_{4} \succ A_{2}$} \\
\hline & $\operatorname{NAS}\left(A_{2}\right)=0$ & \\
\hline & $\operatorname{NAS}\left(A_{3}\right)=1$ & \\
\hline & $\operatorname{NAS}\left(A_{4}\right)=0.0572$ & \\
\hline & $\operatorname{NAS}\left(A_{5}\right)=0.8857$ & \\
\hline \multirow{5}{*}{0.5} & $\operatorname{NAS}\left(A_{1}\right)=0.8355$ & \multirow{5}{*}{$A_{3} \succ A_{1} \succ A_{5} \succ A_{4} \succ A_{2}$} \\
\hline & $\operatorname{NAS}\left(A_{2}\right)=0$ & \\
\hline & $\operatorname{NAS}\left(A_{3}\right)=1$ & \\
\hline & $\operatorname{NAS}\left(A_{4}\right)=0.0861$ & \\
\hline & $\operatorname{NAS}\left(A_{5}\right)=0.8248$ & \\
\hline \multirow{5}{*}{0.7} & $\operatorname{NAS}\left(A_{1}\right)=0.7420$ & \multirow{5}{*}{$A_{3} \succ A_{1} \succ A_{5} \succ A_{4} \succ A_{2}$} \\
\hline & $\operatorname{NAS}\left(A_{2}\right)=0$ & \\
\hline & $\operatorname{NAS}\left(A_{3}\right)=1$ & \\
\hline & $\operatorname{NAS}\left(A_{4}\right)=0.1070$ & \\
\hline & $\operatorname{NAS}\left(A_{4}\right)=0.7364$ & \\
\hline \multirow{5}{*}{0.9} & $\operatorname{NAS}\left(A_{1}\right)=0.6348$ & \multirow{5}{*}{$A_{3} \succ A_{1} \succ A_{5} \succ A_{4} \succ A_{2}$} \\
\hline & $\operatorname{NAS}\left(A_{2}\right)=0$ & \\
\hline & $\operatorname{NAS}\left(A_{3}\right)=1$ & \\
\hline & $\operatorname{NAS}\left(A_{4}\right)=0.1373$ & \\
\hline & $\operatorname{NAS}\left(A_{5}\right)=0.6338$ & \\
\hline
\end{tabular}

It can be seen from Table 19 that as $\lambda$ increases, the normalized appraisal scores increase as well. It shows that when $\lambda>1$, it reflects the degree of risk aversion in the decision-making process, and is used to represent the steeper feature of the loss area of the value function than the gain area. It turns out that the more risk averse the enterprises are, the more $A_{3}$ should be chosen. The $\alpha$ and $\beta$ represent the concave degree of the value function in the gain and loss region respectively. $\alpha$ increases, indicating that DMs have more sensitivity to revenue. The increase of $\beta$ implies that the DMs have more sensitivity to risk. As shown in Table 20 and 21 , the evaluation of the five schemes shows that the decision result is relatively stable, so the enterprises can safely choose scheme $A_{3}$. By analyzing the enhancement EDAS parameters, it makes up for the deficiency of classical EDAS and the enhancement EDAS method makes the decision-making process more bounded rational. 


\section{Conclusions}

Considering that the classical EDAS method can only simulate the DMs' rational part, and the psychological behavior characteristics of decision-makers in the decision-making process are bounded rationality, we extend the classical EDAS method in the following aspects. We integrate $\mathrm{CP}, \mathrm{CPT}$ with decision methods to analyze irrational decision-making. In addition, through case studies, we compared the enhancement EDAS method with the classical EDAS method, the TODIM method based on PT, and the extended TODIM method to prove our research's validity. We also explained that our method could simulate the decision maker's irrational part through sensitivity analysis, which is superior to the classic EDAS method. Although the enhancement EDAS proposed in this article has the advantage in venture capital, DMs' preferences in different fields are different. It is not negligible to study decision-making methods under different psychological backgrounds. In addition, we believe that this research may simulate subsequent research on decision-making methods under the framework of bounded rationality.

\section{Acknowledgements}

The work was supported by the the Humanities and Social Sciences Foundation of Ministry of Education of the People's Republic of China (14YJCZH091).

\section{References}

Armacost, R. L., \& Hosseini, J. C. (1994). Identification of determinant attributes using the analytic hierarchy process. Journal of the Academy of Marketing Science, 22, 383.

https://doi.org/10.1177/0092070394224007

Bagherzadeh, A., \& Gholizadeh, A. (2017). Parametric-based neural networks and TOPSIS modeling in land suitability evaluation for alfalfa production using GIS. Modeling Earth Systems and Environment, 3, 2. https://doi.org/10.1007/s40808-016-0263-y

Barnard, C., \& Simon, H. A. (1947). Administrative behavior. A study of decision-making processes in administrative organization. Free Press. https://www.academia.edu/34589107/ADMINISTRATIVE_ BEHAVIOR_A_Study_of_Decision_Making_Processes_in_Administrative_Organization

Cheng, S. L., \& Chang, H. C. (2006). Multicriteria automatic essay assessor generation by using TOPSIS model and genetic algorithm. In M. Ikeda, K. D. Ashley, \& T. W. Chan (Eds.), Lecture notes in computer science: Vol. 4053. Intelligent tutoring systems, proceedings (pp. 11-20). Springer. https://doi.org/10.1007/11774303_2

Evans, J. R. (1984). Sensitivity analysis in decision theory. Decision Sciences, 15(2), 239-247. https://doi.org/10.1111/j.1540-5915.1984.tb01211.x

Fallahpour, A., Olugu, E. U., \& Musa, S. N. (2017). A hybrid model for supplier selection: Integration of AHP and multi expression programming (MEP). Neural Computing \& Applications, 28, 499-504. https://doi.org/10.1007/s00521-015-2078-6

Fishburn, P. C., Murphy, A. H., \& Isaacs, H. H. (1968). Sensitivity of decisions to probability estimation errors: A reexamination. Operations Research, 16(2), 254-267. https://doi.org/10.1287/opre.16.2.254

Gomes, L., \& Lima, M. (1992). TODIM: Basics and application to multicriteria ranking of projects with environmental impacts. Foundations of Computing and Decision Sciences, 16, 113-127. 
Gomes, L., \& Rangel, L. A. D. (2009). An application of the TODIM method to the multicriteria rental evaluation of residential properties. European Journal of Operational Research, 193(1), 204-211. https://doi.org/10.1016/j.ejor.2007.10.046

Hashiyama, T., Furuhashi, T., \& Uchikawa, Y. (1993). A study on a multi-attribute decision making process using fuzzy neural network. In Proceedings of the Korean Institute of Intelligent Systems Conference (pp. 810-813). Korean Institute of Intelligent Systems.

He, T., Wei, G., Lu, J., Wu, J., Wei, C., \& Guo, Y. (2020). A novel EDAS based method for multiple attribute group decision making with pythagorean 2-tuple linguistic information. Technological and Economic Development of Economy, 26(6), 1125-1138. https://doi.org/10.3846/tede.2020.12733

He, Y., Lei, F., Wei, G. W., Wang, R., Wu, J., \& Wei, C. (2019). EDAS method for multiple attribute group decision making with probabilistic uncertain linguistic information and its application to green supplier selection. International Journal of Computational Intelligence Systems, 12(2), 1361-1370. https://doi.org/10.2991/ijcis.d.191028.001

Hillier, F. S., Lieberman, G. J., Nag, B., \& Basu, P. (2012). Introduction to operations research. Tata McGraw-Hill Education. https://www.iimcal.ac.in/sites/all/files/pdfs/tmh-book-cover.pdf

Keshavarz Ghorabaee, M., Zavadskas, E. K., Amiri, M., \& Turskis, Z. (2016). Extended EDAS method for fuzzy multi-criteria decision-making: An application to supplier selection. International Journal of Computers Communications \& Control, 11(3), 358-371. https://doi.org/10.15837/ijccc.2016.3.2557

Keshavarz Ghorabaee, M., Zavadskas, E. K., Olfat, L., \& Turskis, Z. (2015). Multi-criteria inventory classification using a new method of evaluation based on distance from average solution (EDAS). Informatica, 26(3), 435-451. https://doi.org/10.15388/Informatica.2015.57

Lahdelma, R., \& Salminen, P. (2009). Prospect theory and stochastic multicriteria acceptability analysis (SMAA). Omega, 37(5), 961-971. https://doi.org/10.1016/j.omega.2008.09.001

Liu, P., Jin, F., Zhang, X., Su, Y., \& Wang, M. (2011). Research on the multi-attribute decision-making under risk with interval probability based on prospect theory and the uncertain linguistic variables. Knowledge-Based Systems, 24(4), 554-561. https://doi.org/10.1016/j.knosys.2011.01.010

Liu, P., \& Zhang, X. (2010). The study on multi-attribute decision-making with risk based on linguistic variable. International Journal of Computational Intelligence Systems, 3(5), 601-609. https://doi.org/10.2991/ijcis.2010.3.5.9

Malik, N., \& Shabir, M. (2019). Rough fuzzy bipolar soft sets and application in decision-making problems. Soft Computing, 23, 1603-1614. https://doi.org/10.1007/s00500-017-2883-1

Masuda, T. (1990). Hierarchical sensitivity analysis of priority used in analytic hierarchy process. International Journal of Systems Science, 21(2), 415-427. https://doi.org/10.1080/00207729008910371

Morgenstern, O., \& Von Neumann, J. (1953). Theory of games and economic behavior. Princeton University Press.

Myers, J. H., \& Alpert, M. I. (1968). Determinant buying attitudes: meaning and measurement. Journal of Marketing, 32(4), 13-20. https://doi.org/10.1177/002224296803200404

Pawlak, Z., \& Sowinski, R. (1994). Rough set approach to multi-attribute decision analysis. European Journal of Operational Research, 72(3), 443-459. https://doi.org/10.1016/0377-2217(94)90415-4

Ren, Z. L., Xu, Z. S., \& Wang, H. (2019). The strategy selection problem on artificial intelligence with an integrated VIKOR and AHP method under probabilistic dual hesitant fuzzy information. IEEE Access, 7, 103979-103999. https://doi.org/10.1109/ACCESS.2019.2931405

Rostamzadeh, R., Esmaeili, A., Nia, A. S., Saparauskas, J., \& Keshavarz Ghorabaee, M. (2017). A fuzzy ARAS method for supply chain management performance measurement in SMEs under uncertainty. Transformations in Business \& Economics, 16, 319-348. https://www.researchgate.net/ publication/321797571_A_Fuzzy_ARAS_Method_for_Supply_Chain_Management_Performance_ Measurement_in_SMEs_under_Uncertainty 
Roy, J., Sharma, H. K., Kar, S., Zavadskas, E. K., \& Saparauskas, J. (2019). An extended COPRAS model for multi-criteria decision-making problems and its application in web-based hotel evaluation and selection. Economic Research-Ekonomska Istrazivanja, 32(1), 219-253.

https://doi.org/10.1080/1331677X.2018.1543054

Saaty, T. L. (1977). A scaling method for priorities in hierarchical structures. Journal of Mathematical Psychology, 15(3), 234-281. https://doi.org/10.1016/0022-2496(77)90033-5

Salminen, P. (1994). Solving the discrete multiple criteria problem using linear prospect theory. European Journal of Operational Research, 72(1), 146-154. https://doi.org/10.1016/S0377-2217(12)80001-4

Schmidt, U., Starmer, C., \& Sugden, R. (2008). Third-generation prospect theory. Journal of Risk and Uncertainty, 36, 203. https://doi.org/10.1007/s11166-008-9040-2

Schmidt, U., \& Zank, H. (2009). A simple model of cumulative prospect theory. Journal of Mathematical Economics, 45(3-4), 308-319. https://doi.org/10.1016/j.jmateco.2008.12.001

Starr, M. K. (1966). A discussion of some normative criteria for decision-making under uncertainty. IMR; Industrial Management Review (pre-1986), 8, 71.

Tabatabaei, M. H., Amiri, M., Firouzabadi, S., Ghahremanloo, M., Keshavarz-Ghorabaee, M., \& Saparauskas, J. (2019). A new group decision-making model based on BWM and its application to managerial problems. Transformations in Business \& Economics, 18(2), 197-214. https://www. researchgate.net/publication/333666237_A_New_Group_Decision-Making_Model_based_on_ BWM_and_its_Application_to_Managerial_Problems

Tian, X., Xu, Z., Gu, J., \& Herrera-Viedma, E. (2018). How to select a promising enterprise for venture capitalists with prospect theory under intuitionistic fuzzy circumstance? Applied Soft Computing, 67, 756-763. https://doi.org/10.1016/j.asoc.2017.04.027

Tian, X. L., Xu, Z. S., \& Gu, J. (2019). An extended TODIM based on cumulative prospect theory and its application in venture capital. Informatica, 30(2), 413-429. https://doi.org/10.15388/Informatica.2019.212

Tversky, A., \& Kahneman, D. (1979). Prospect theory: An analysis of decision under risk. Econometrica, 47(2), 263-291. https://doi.org/10.2307/1914185

Tversky, A., \& Kahneman, D. (1992). Advances in prospect theory: Cumulative representation of uncertainty. Journal of Risk and Uncertainty, 5, 297-323. https://doi.org/10.1007/BF00122574

Wakker, K. (2007). Astrodynamics I. Lecture Notes AE4-874, Part, 1. Delft University of Technology, Faculty of Aerospace Engineering. The Netherlands.

Wang, J. Q., \& Zhang, Z. (2009). Aggregation operators on intuitionistic trapezoidal fuzzy number and its application to multi-criteria decision making problems. Journal of Systems Engineering and Electronics, 20(2), 321-326. https://www.researchgate.net/publication/260650574_Aggregation_operators_on_intuitionistic_trapezoidal_fuzzy_number_and_its_application_to_multi-criteria_decision_making_problems

Wang, L., Wang, Y.-M., \& Martínez, L. (2017). A group decision method based on prospect theory for emergency situations. Information Sciences, 418, 119-135. https://doi.org/10.1016/j.ins.2017.07.037

Wang, S., Wei, G., Wu, J., Wei, C., \& Guo, Y. (2021). Model for selection of hospital constructions with probabilistic linguistic GRP method. Journal of Intelligent \& Fuzzy Systems, 40(1), 1245-1259. https://doi.org/10.3233/JIFS-201543

Wei, C., Wu, J., Guo, Y., \& Wei, G. (2021a). Green supplier selection based on CODAS method in probabilistic uncertain linguistic environment. Technological and Economic Development of Economy, 27(3), 530-549. https://doi.org/10.3846/tede.2021.14078

Wei, G., Wu, J., Guo, Y., Wang, J., \& Wei, C. (2021b). An extended COPRAS model for multiple attribute group decision making based on single-valued neutrosophic 2-tuple linguistic environment. Technological and Economic Development of Economy, 27(2), 353-368.

https://doi.org/10.3846/tede.2021.14057 
Yoon, K., \& Hwang, C. L. (1981). TOPSIS (technique for order preference by similarity to ideal solution) - a multiple attribute decision making. In Multiple attribute decision making: Methods and applications, a state-of-the-at survey. Springer Verlag.

Zhang, Y., Wei, G., Guo, Y., \& Wei, C. (2021). TODIM method based on cumulative prospect theory for multiple attribute group decision-making under 2-tuple linguistic Pythagorean fuzzy environment. International Journal of Intelligent Systems, 36(6), 2548-2571. https://doi.org/10.1002/int.22393

Zhao, M., Wei, G., Wei, C., \& Guo, Y. (2021a). CPT-TODIM method for bipolar fuzzy multi-attribute group decision making and its application to network security service provider selection. International Journal of Intelligent Systems, 36(5), 1943-1969. https://doi.org/10.1002/int.22367

Zhao, M., Wei, G., Wei, C., Wu, J., \& Wei, Y. (2021b). Extended CPT-TODIM method for intervalvalued intuitionistic fuzzy MAGDM and its application to urban ecological risk assessment. Journal of Intelligent \& Fuzzy Systems, 40(3), 4091-4106. https://doi.org/10.3233/JIFS-200534

Zhao, M., Wei, G., Wu, J., Guo, Y., \& Wei, C. (2021c). TODIM method for multiple attribute group decision making based on cumulative prospect theory with 2-tuple linguistic neutrosophic sets. International Journal of Intelligent Systems, 36(3), 1199-1222. https://doi.org/10.1002/int.22338

Zhao, M. W., Wei, G. W., Wei, C., \& Wu, J. (2021d). Pythagorean fuzzy TODIM method based on the cumulative prospect theory for MAGDM and its application on risk assessment of science and technology projects. International Journal of Fuzzy Systems. https://doi.org/10.1007/s40815-020-00986-8 